\title{
High-Dose Oral Ibuprofen in Treatment of Patent Ductus Arteriosus in Full-Term Neonates
}

\author{
Shahnaz Pourarian ${ }^{1}$; Mehrdad Rezaie ${ }^{1}$; Hamid Amoozgar ${ }^{2,}$; Ali-Mohammad Shakiba ${ }^{2}$; \\ Mohammad-Reza Edraki ${ }^{2}$; Nima Mehdizadegan ${ }^{2}$ \\ ${ }^{1}$ Department of Pediatrics, Neonatology Research Center, Shiraz University of Medical Sciences, Shiraz, IR Iran \\ ${ }^{2}$ Cardiac and Neonatology Research Center, Shiraz University of Medical Sciences, Shiraz, IR Iran \\ *Corresponding author: Hamid Amoozgar, Cardiac and Neonatology Research Center, Shiraz University of Medical Sciences, Shiraz, IR Iran. E-mail: amozgah@sums.ac.ir \\ Received: April 16, 2015; Accepted: April 27, 2015
}

\begin{abstract}
Background: Patent ductus arteriosus(PDA) is an important risk for heart failure due to left to right shunt in term neonates.
Objectives: In this study, we evaluated the effect of high dose ibuprofen in closure of PDA in term neonates.

Patients and Methods:We used double dose ibuprofen $(20 \mathrm{mg} / \mathrm{kg}, 10 \mathrm{mg} / \mathrm{kg}$, and $10 \mathrm{mg} / \mathrm{kg}$ ) for $3-30$ day old term neonates with PDA who were admitted in the neonatal wards of Shiraz University of Medical Sciences. The results of this study were compared to the data of the previous study in our center which used the low dose of ibuprofen (10 mg/kg, $5 \mathrm{mg} / \mathrm{kg}$, and $5 \mathrm{mg} / \mathrm{kg}$ ).

Results: 29 full term neonates received high-dose ibuprofen, in 18 neonates, PDA was closed after 4 days (62.1\% versus $43.3 \%$ for the standard dose and $4.7 \%$ for the control group in the previous study) $(\mathrm{P}=0.001)$. The results showed no significant correlation between the closure rateand gestational age, postnatal age, sex, and weight. In the $4^{\text {th }}$ day of treatment, size of the pulmonic end of ductus arteriosus decreased from $2.09 \mathrm{~mm}$ to $0.77 \mathrm{~mm}$ compared to $1.68 \mathrm{~mm}$ to $0.81 \mathrm{~mm}$ in the standard dose of oral ibuprofen and $2.1 \mathrm{~mm}$ to $1.4 \mathrm{~mm}$ in the control $\operatorname{group}(\mathrm{P}=0.046)$.
\end{abstract}

Conclusions: This study indicated that high-dose oral ibuprofen was more effective in closing or decreasing the size of PDA.

Keywords: Term Neonate; High Dose Oral Ibuprofen; Ductus Arteriosus; Patient

\section{Background}

Ductus arteriosus (DA) is a fetal vascular connection between the main pulmonary artery and the aorta that diverts blood away from the pulmonary bed. Histologically, ductal tissue differs from that of the adjacent aorta and pulmonary artery (1). The fetal DA is kept patent by low arterial oxygen content and circulating prostaglandin E2 (PGE2), which is produced in part by the placenta (2). At birth, the rise in systemic arterial oxygen tension and a decrease in circulating PGE2 levels trigger ductal constriction.

Although the mechanism that causes active ductal constriction is not known, gene transfer studies suggest that it is mediated by an oxygen-sensitive potassium channel (3). After delivery, circulating PGE2 levels fall because of reduced production following the removal of the placenta and increased PGE2 clearance due to increase in the circulating levels of prostaglandin dehydrogenase $(4,5)$. Removal of the strong vasodilatory effect of PGE2 is sensed by the PGE2 receptor (EP4) and promotes further constriction of the ductus $(6,7)$. The incidence rate of an isolated patent ductus arteriosus (PDA) among term infants has been reported to range from 0.03 to 0.08 percent (8). The hemodynamic conse- quences of the PDAs can be categorized by the degree of left-to-right shunting based upon the pulmonary to systemic flow ratio (Qp: Qs) (9). The diagnosis of PDA is usually based upon its clinical findings and is typically confirmed by echocardiography. Cardiac catheterization and angiography are generally only necessary when percutaneous therapy is being considered or in the context of more complex congenital heart disease.

The individuals with PDA have increased morbidity and mortality, primarily due to heart failure and rarely infective endocarditis. Additionally, pulmonary vascular disease is an uncommon problem. Also, PDA can be complicated with chronic lung disease, intraventricular hemorrhage, and necrotizing enterocolitis due to severe left to right shunt (10). Surgical or interventional closing of PDA is usually recommended after the age of 6 months. Conventional surgical closure or video-assisted thoracoscopic surgery is appropriate for the infants with a moderate to large PDA (5). Surgical ligation of the DA has been associated with increased morbidity and adverse neurodevelopmental outcome (11). Yet, a relatively higher incidence of vocal cord paralysis has been reported postoperatively in the infants

Copyright (C) 2015, Growth \& Development Research Center. This is an open-access article distributed under the terms of the Creative Commons Attribution-NonCommercial 4.0 International License (http://creativecommons.org/licenses/by-nc/4.0/) which permits copy and redistribute the material just in noncommercial usages, provided the original work is properly cited. 
with PDA (12). Some reports have shown indomethacin, a cyclooxygenase inhibitor, to be useful in closing PDA.

In our center, in a prospective case-control study, 51 neonates with PDA and gestational age of 37 weeks or more were evaluated in order to determine the effectiveness of the standard dose (10 - 5 - $5 \mathrm{mg} / \mathrm{kg} /$ day for 3 days) of oral ibuprofen. In that study, 30 neonates received ibuprofen and 21 neonates received the placebo. After 4 days of starting the medication, DA was closed in $43.3 \%$ of the case group subjects and $4.7 \%$ of the control group ones. The results of the study showed that PDA was closed more and faster in the neonates receiving oral ibuprofen compared to the control group (13).

\section{Objectives}

According to a study that showed more and faster closure of PDA with use of high-dose ibuprofen in preterm neonates (14), we designed this study to determine whether high-dose oral ibuprofen was more effective in closing PDA in full-term neonates.

\section{Patients and Methods}

The present study was performed on 33 neonates with gestational age of 37 weeks or more and postnatal age of 3 to 30 days who were suffering from PDA and were admitted in the neonatal and pediatric cardiologic centers of Shiraz University of Medical Sciences. This study was designed similar to a previous study which compared the effect of oral ibuprofen on full term neonates and a control group in this neonatal center. We evaluated the effect of high dose ibuprofen in closure of PDA in term neonates. In this clinical trial, we used double dose ibuprofen $(20 \mathrm{mg} / \mathrm{kg}, 10 \mathrm{mg} / \mathrm{kg}$, and $10 \mathrm{mg} / \mathrm{kg})$ for 3 - 30 day old term neonates with PDA who were admitted to the neonatal wards of University of Medical sciences. The results of this study were compared to the data of the previous study in our center which used the low dose of ibuprofen $(10 \mathrm{mg} / \mathrm{kg}, 5 \mathrm{mg} / \mathrm{kg}$, and $5 \mathrm{mg} / \mathrm{kg}$ ) for 30 full term neonates and compared with 21 neonates who received placebo in a randomized control trial. Figure 1 shows consort flow diagram of the study. The study was approved by the ethics committee of the university (code number: CT-91-6370). All the patients were diagnosed clinically by a neonatologist and confirmed by a pediatric cardiologist with echocardiography. Four neonates were excluded from the study because of death due to the associated severe medical problems before taking ibuprofen. Overall, 29 neonates (male to female ratio: 66.6\%) received high dose ibuprofen (20 - $10-10 \mathrm{mg} / \mathrm{kg} /$ day) for 3 days, as an oral suspension $(100 \mathrm{mg} / 5 \mathrm{~mL}$; Hakim Pharmaceutical, Tehran, Iran, 75-HM-30). Before and after the 4th day of medication, blood urea nitrogen, creatinine, and platelet levels were measured. Additionally, the patients were monitored for oliguria, bleeding, gastrointestinal discomfort, and other side effects of ibuprofen. Echocardiography was performed with a Vivid 3 ultrasound ma- chine (GE Vingmed, Horten, Norway) using $7 \mathrm{MHz}$ probes on days one and four of the study. The neonates were also evaluated regarding the pressure gradient, size of PDA, left atrial to aortic ratio, and development of pulmonary hypertension.

The data were recorded on a form especially designed by the neonatologist and pediatric cardiologist. Then, they were entered into the SPSS statistical software, v.18 (SPSS Inc. Chicago, IL) and analyzed using Chi-square, Kruskal-Wallis, ANOVA and, student t-tests.

\section{Results}

The results revealed no statistically significant difference between the neonates who received high dose oral ibuprofen and those in our previous study regarding the base line demographic, paraclinical, and echocardiographic parameters, except for platelet count (Tables 1 and 2). Echocardiographic evaluation on the $4^{\text {th }}$ day of the treatment revealed 62.1\% PDA closing. However, this measure was obtained as $43.3 \%$ in the group receiving the standard dose of oral ibuprofen and $4.7 \%$ in the placebo group in the previous study ( $\mathrm{P}=0.001$, Figure 2$)$ (13). Besides, diameter of the pulmonic end of DA decreased from $2.09 \pm 0.56 \mathrm{~mm}$ to $0.77 \pm 1.10 \mathrm{~mm}$ in the neonates who received high dose oral ibuprofen $(\mathrm{P}<0.001)$. In this group, the average diameter of DA decreased by $1.32 \mathrm{~mm}$, while it was decreased by $0.87 \mathrm{~mm}$ and $0.7 \mathrm{~mm}$ in the neonates who received the standard dose ibuprofen and those in the control group, respectively $(\mathrm{P}=0.046)$. The results demonstrated no significant correlation between the decrease in PDA size and the neonates' gestational and postnatal age. Furthermore, no significant adverse effects of ibuprofen were reported. Only two neonates had a mild feeding intolerance, but they did not need any treatment. It should also be mentioned that the same event was detected in the low dose group, as well.

\section{Discussion}

The studies conducted by Gittenberger and Groot (15) showed a series of physiological changes leading to functional and anatomical PDA closing in newborns. If these changes do not occur due to duct immaturity, perinatal and postnatal problems, or ductal malformations, the DA will not be closed. The first goal of treatment of PDA in term neonates is controlling the complications (congestive heart failure). Indomethacin is the most common drug used to close PDA despite having some adverse effects on renal function. Ibuprofen is another effective cyclooxygenase inhibitor used to close PDA which is accompanied by less renal adverse effects. Traditionally, PDA in full-term newborns was surgically treated that had some morbidity. To date, some studies have been conducted on using indomethacin and ibuprofen (intravenous and oral) to treat PDA in pre-term and term neonates. McCarthy et al. (16) demonstrated the effect of indomethacin therapy on PDA in four newborn infants with birth 
Pourarian S et al.

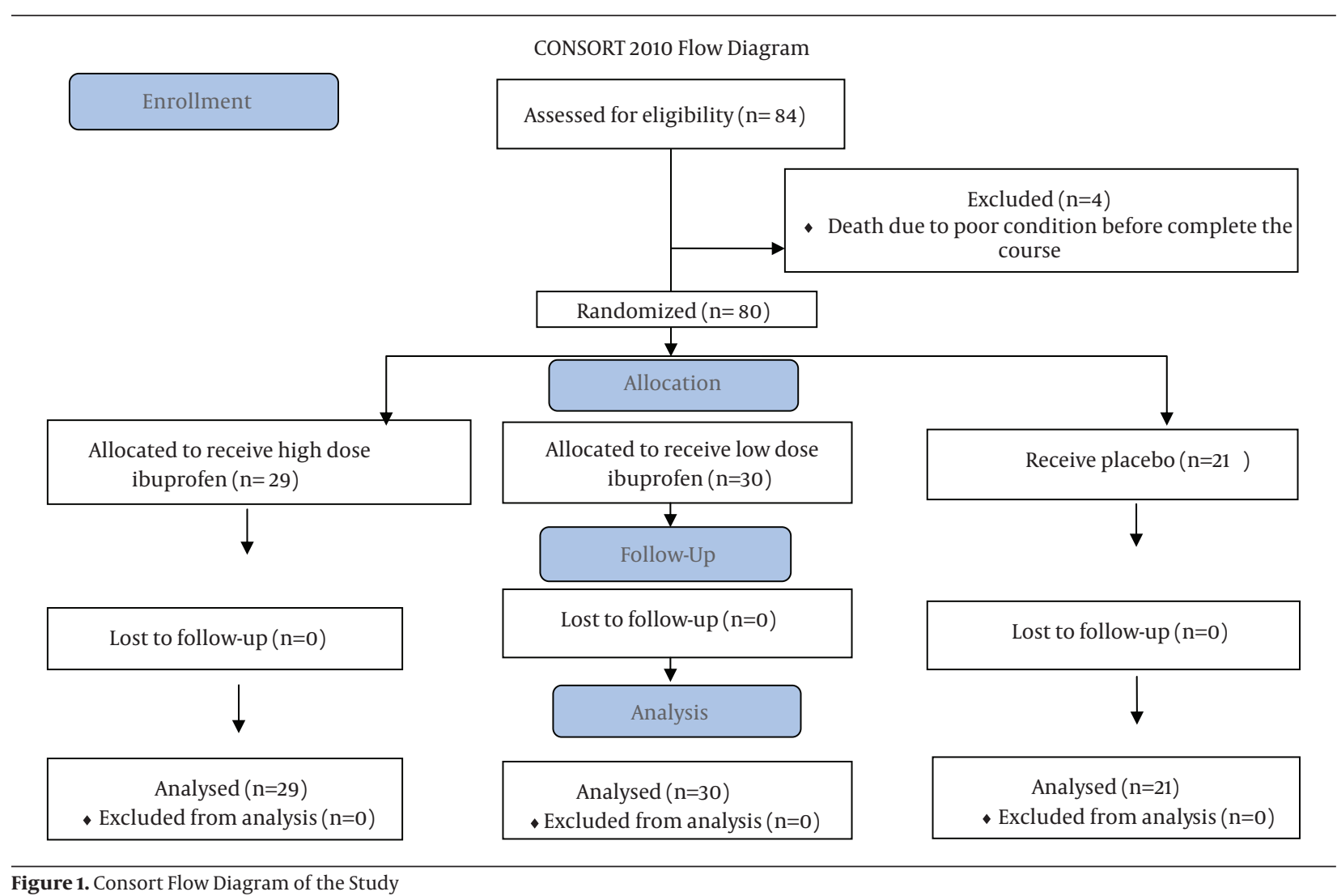

Table 1. Demographic and Para-Clinical Parameters in Neonates Who Were Treated With High Dose Ibuprofen, Standard Dose Ibuprofen and Placebo ${ }^{a}$

\begin{tabular}{|c|c|c|c|c|}
\hline Parameter & $\begin{array}{c}\text { High Dose } \\
\text { Ibuprofen }(n=29) \\
\end{array}$ & $\begin{array}{c}\text { Standard Dose } \\
\text { Ibuprofen }(n=30)\end{array}$ & $\operatorname{Placebo}(\mathbf{n}=\mathbf{2 1})$ & P Value \\
\hline Gender $^{\mathrm{b}}$ & & & & 0.271 \\
\hline Male & $12(41.4)$ & $14(46.7)$ & $12(57.1)$ & \\
\hline Female & $7(58.6)$ & $16(53.3)$ & $9(42.9)$ & \\
\hline Age, $\mathrm{d}^{\mathrm{C}}$ & $7.9 \pm 7.34$ & $10.73 \pm 8.51$ & $10.43 \pm 9.2$ & 0.349 \\
\hline Weight, $\mathrm{g}^{\mathrm{C}}$ & $3172.90 \pm 528.55$ & $3368 \pm 573.1$ & $3391.43 \pm 635.27$ & 0.313 \\
\hline Blood urea nitrogen (mg\%) before treatment & $13.32(5.22)$ & $16.07(11.3)$ & $14.19(6.60)$ & 0.532 \\
\hline Blood urea nitrogen (mg\%) after treatment & $1025(6.54)$ & $15.13(6.53)$ & $12.34(11.16)$ & 0.088 \\
\hline Creatinine (mg\%) before treatment & $0.52(0.29)$ & $0.66(0.36)$ & $0.71(0.36)$ & 0.175 \\
\hline Creatinine (mg\%) after treatment & $0.59(0.25)$ & $0.57(0.21)$ & $0.65(0.31)$ & 0.073 \\
\hline Platelet $(\times 1000)$ before treatment & $234.530(81.328)$ & $162.167(64.137)$ & $194.904(22.400)$ & 0.009 \\
\hline Platelet $(\times 1000)$ after treatment & $257.070(99.084)$ & $177.714(60.238)$ & $131.600(22.400)$ & 0.003 \\
\hline
\end{tabular}

Table 2. Echocardiographic Findings in Neonates Who Were Treated With High Dose Ibuprofen, Standard Dose Ibuprofen and Placebo $^{\text {a }}$

\begin{tabular}{|c|c|c|c|c|}
\hline Echocardiographic Findings & $\begin{array}{c}\text { High Dose Ibuprofen } \\
(\mathbf{n}=29)\end{array}$ & $\begin{array}{c}\text { Standard Dose Ibuprofen } \\
(\mathbf{n}=\mathbf{3 0})\end{array}$ & $\operatorname{Placebo}(\mathbf{n}=\mathbf{2 1})$ & P Value \\
\hline Size of pulmonic end of PDA, $\mathrm{mm}^{\mathrm{b}}$ & $2.09 \pm 0.56$ & $1.68 \pm 0.87$ & $2.10 \pm 0.8$ & 0.058 \\
\hline Systolic gradient, $\mathbf{m m H g}$ b & $24.2 \pm 9.7$ & $29.3 \pm 8.1$ & $29.5 \pm 11.4$ & 0.100 \\
\hline Diastolic gradient, mmHg ${ }^{\text {b }}$ & $14.6 \pm 4.7$ & $20.1 \pm 6.7$ & $21.7 \pm 9.9$ & 0.062 \\
\hline Left atrial/Aortic ratio ${ }^{b}$ & $1.40 \pm 0.23$ & $1.52 \pm 0.27$ & $1.39 \pm 0.19$ & 0.107 \\
\hline
\end{tabular}

a Placebo and standard dose data are from article published in pediatr cardiol 2010;31:40 - 43 (13).

$\mathrm{b}$ Values are presented as mean \pm SD. 


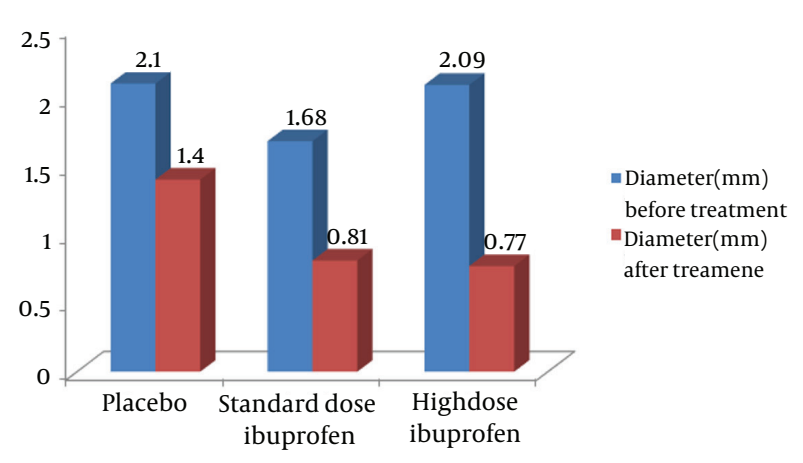

Figure 2. Comparing the Diameter of the Pulmonic End of Ductus Arteriosus in the Full-Term Neonates Treated With Oral Ibuprofen (Standard Dose - High Dose) and Those in the Control Group Studied in Two Researches Performed at Shiraz University of Medical Sciences

weight of 1500 - 2075 grams that were born at the gestational age of 35 weeks or above. Moreover, Watanabe et al. (17) reported the closure of PDA in 4 out of 7 fullterm infants with birth weight of 2500 gr or more that were treated with indomethacin. Another study reported a success rate of $61 \%$ in decreasing the size or closure of PDA using intra-venous indomethacin in 41 full-term neonates (18). Rudolph (19) also indicated a closure rate of approximately $80 \%$ in premature neonates after using 0.1 - $0.2 \mathrm{mg} / \mathrm{kg}$ intravenous indomethacin every 12 - 24 hours. Indomethacin, a prostaglandin synthetize inhibitor, has been shown to close the DA in a large number of premature infants up to 14 days of age and occasionally as late as one month of age. Yet, its contraindications include renal failure, active bleeding, and significant thrombocytopenia. It should be noted that failure of indomethacin therapy is mostly associated with extreme immaturity and greater postnatal age at the beginning of the therapy (20).

Thomas et al. stated that the effect of ibuprofen on closing the PDA was similar to that of indomethacin (21). In a prospective case-control study in our neonatology ward, after 4 days of starting the standard dose of oral ibuprofen in 51 full-term neonates, DA was closed in $43.3 \%$ of the case group subjects and $4.7 \%$ of the control group ones. The results also showed that PDA was closed more and faster in the full term neonates who had received oral ibuprofen (13). Moreover, high-dose ibuprofen was more effective in closure of PDA in preterm neonates (14). In the current study, we studied 29 term neonates under exactly the same conditions as the previous study, but using high dose oral ibuprofen. On the $4^{\text {th }}$ day after starting the treatment, 62.1\% of the neonates showed PDA closure, which was statistically higher compared to the control group, but not the group receiving the standard dose of ibuprofen $(\mathrm{P}<0.0008)$. Overall, comparing the results of these two studies revealed another important aspect of treatment with ibuprofen. In our new study, the average diameter of the pulmonic end of DAchanged from $2.09 \mathrm{~mm}$ to $0.77 \mathrm{~mm}$ (decreased $1.32 \mathrm{~mm}$ ) after the treatment. However, in the previous study using the standard dose of oral ibuprofen, this change was much less (from $1.68 \mathrm{~mm}$ to $0.81 \mathrm{~mm}$ on $4^{\text {th }}$ day after the treatment, which is $0.87 \mathrm{~mm}$ ). This shows that high dose oral ibuprofen may be more effective in controlling PDA symptoms. In addition, using high dose ibuprofen was not accompanied by any adverse effects.

High dose oral ibuprofen was effective in closing PDA in full-term neonates who needed treatment. In cases that PDA was not closed after low dose oral ibuprofen, the size of DA was significantly decreased following treatment with high dose ibuprofen. Therefore, we may recommend using high dose oral ibuprofen in full-term neonates with PDA before choosing the surgical approach. It can also be the first choice in the patients with large PDA to control symptoms.

\subsection{Limitations of the Study}

Small sample size and not blinding the historical cohort of group seem to be major limitations of the study.

\section{Acknowledgements}

The authors would like to thank the center of neonatal researches of Shiraz University of Medical Sciences and the research vice-chancellor of Shiraz University of Medical Sciences for their support. They are also grateful to Ms. A. Keivanshekouh at the research improvement center of Shiraz University of Medical Sciences for improving the use of English in the manuscript. This clinical trial was approved by ethic committee of Shiraz University of Medical sciences with code number: CT-91-6370 and registered at clinical trial registry of Iran with code number: IRCT20141122200229N1.

\section{References}

1. Allen HD, Driscoll DJ, Shaddy RE, Feltes T. Moss and Adams' Heart Disease in Infants, Children, and Adolescents: Including the Fetus and Young Adult. 7 ed. Philadelphia: Lippincott Williams and Wilkins; 2007.

2. Smith GC. The pharmacology of the ductus arteriosus. Pharmacol Rev. 1998;50(1):35-58.

3. Thebaud B, Michelakis ED, Wu XC, Moudgil R, Kuzyk M, Dyck JR, et al. Oxygen-sensitive Kv channel gene transfer confers oxygen responsiveness to preterm rabbit and remodeled human ductus arteriosus: implications for infants with patent ductus arteriosus. Circulation. 2004;110(11):1372-9.

4. Coggins KG, Latour A, Nguyen MS, Audoly L, Coffman TM, Koller BH. Metabolism of PGE2 by prostaglandin dehydrogenase is essential for remodeling the ductus arteriosus. Nat Med. 2002;8(2):91-2.

5. Loftin CD, Trivedi DB, Langenbach R. Cyclooxygenase-1-selective inhibition prolongs gestation in mice without adverse effects on the ductus arteriosus. J Clin Invest. 2002;110(4):549-57.

6. Nguyen M, Camenisch T, Snouwaert JN, Hicks E, Coffman TM, Anderson PA, et al. The prostaglandin receptor EP4 triggers remodelling of the cardiovascular system at birth. Nature.1997;390(6655):78-81

7. Segi E, Sugimoto Y, Yamasaki A, Aze Y, Oida H, Nishimura T, et al. Patent ductus arteriosus and neonatal death in prostaglandin receptor EP4-deficient mice. Biochem Biophys Res Commun. 1998;246(1):7-12.

8. Hoffman JI, Kaplan S. The incidence of congenital heart disease. J Am Coll Cardiol. 2002;39(12):1890-900.

9. Mullins CE. Patent ductus arteriosus. In: Garson A, Bricker JT, McNamara DG, editors. The Science and Practice of Pediatric Cardiology. Philadelphia: Lea \& Febiger; 1990. p. 1055-6.

10. Milliken JC, D'Souza G. Patent Ductus Arteriosus. Review Article eMedicine cardiology. 2007;115(8):1039-50.

11. Madan JC, Kendrick D, Hagadorn JI, Frantz I3, National Institute 
of Child H, Human Development Neonatal Research N. Patent ductus arteriosus therapy: impact on neonatal and 18-month outcome. Pediatrics. 2009;123(2):674-81.

12. Benjamin JR, Smith PB, Cotten CM, Jaggers J, Goldstein RF, Malcolm WF. Long-term morbidities associated with vocal cord paralysis after surgical closure of a patent ductus arteriosus in extremely low birth weight infants. J Perinatol. 2010;30(6):408-13.

13. Amoozgar H, Ghodstehrani M, Pishva N. Oral ibuprofen and ductus arteriosus closure in full-term neonates: a prospective casecontrol study. Pediatr Cardiol. 2010;31(1):40-3.

14. Timethy M, Hugh D. , Allen DJ, Driscoll RES. Physiology of the preterm and term infant. Moss and Adams' Heart Disease in Infants, Children, and Adolescents. 7 ed. Philadelphia: Lippincott Williams and Wilkins; 2008. pp. 440-1.

15. Gittenberger-de Groot AC. Persistent ductus arteriosus: most probably a primary congenital malformation. Br Heart $J$. 1977;39(6):610-8.

16. McCarthy JS, Zies LG, Gelband H. Age-dependent closure of the patent ductus arteriosus by indomethacin. Pediatrics. 1978;62(5):706-12.

17. Watanabe K, Tomita H, Ono Y, Yamada O, Kurosaki K, Echigo S. Intravenous indomethacin therapy in infants with a patent ductus arteriosus complicating other congenital heart defects. Circ J. 2003;67(9):750-2.

18. Takami T, Yoda H, Kawakami T, Yamamura H, Nakanishi T, Nakazawa $\mathrm{M}$, et al. Usefulness of indomethacin for patent ductus arteriosus in full-term infants. Pediatr Cardiol. 2007;28(1):46-50.

19. Rudolph AM. The ductus arteriosus and persistent patency of the ductus arteriosus. In: Rudolph AM editor. Congenital Disease of The Heart. 2 ed. Armonk, NY: Future; 2001. pp. 155-96.

20. Weiss H, Cooper B, Brook M, Schlueter M, Clyman R. Factors determining reopening of the ductus arteriosus after successful clinical closure with indomethacin. J Pediatr.1995;127(3):466-71.

21. Thomas RL, Parker GC, Van Overmeire B, Aranda JV. A meta-analysis of ibuprofen versus indomethacin for closure of patent ductus arteriosus. Eur J Pediatr. 2005;164(3):135-40. 